\title{
AS PRÁtICAS PEDAGÓgICAS NO ENSINO REMOTO E A FORMAÇÃO DOCENTE NA COVID-19
}

\section{ARTIGO ORIGINAL}

BRAZIL, Paulo Henrique de Assis ${ }^{1}$, BRAZIL, Danielle Farias Vitorino², BARBOSA, Claudio Sales ${ }^{3}$, MACIEL, Maria da Conceição Carvalho ${ }^{4}$

BRAZIL, Paulo Henrique de Assis. Et al. As práticas pedagógicas no ensino remoto e a formação docente na Covid-19. Revista Científica Multidisciplinar Núcleo do Conhecimento. Ano. 06, Ed. 09, Vol. 06, pp. 130-140. Setembro 2021. ISSN: 2448-0959, Link de acesso:

https://www.nucleodoconhecimento.com.br/educacao/a-formacao-docente, DOI: 10.32749/nucleodoconhecimento.com.br/educacao/a-formacao-docente

\section{RESUMO}

Este ensaio teve como tema discutir as práticas pedagógicas no ensino remoto e a formação docente na COVID-19, demostrando uma estratégia para que o ensino e aprendizado não fosse prejudicado devido à pandemia. A problemática da pesquisa é dada pelo seguinte questionamento: qual a possível solução encontrada para vencer os desafios que surgiram, em meio a pandemia do COVID-19 no Brasil, nas práticas pedagógicas docentes para que os calendários acadêmicos não sofressem alterações? Para solucionar a problemática o estudo teve, através da abordagem qualitativa realizada por meio de pesquisa bibliográfica, como objetivo geral, apresentar a importância na utilização das TIC's nas práticas pedagógicas docentes para o desenvolvimento do ensino e aprendizagem durante a Covid-19. O trabalho,

\footnotetext{
${ }^{1}$ Mestre em Economia pela UFPB, Pós Graduado em Contabilidade Pública pela Universidade Gama Filho - UGF /RJ. Graduado em Ciências Contábeis pela UFRN. ORCID: https://orcid.org/0000-0002-6890-4669.

2 Pós-Graduada em Contabilidade Pública pela Universidade Gama Filho - UGF /RJ; Graduada em Ciências Contábeis pela UFRN. ORCID: https://orcid.org/0000-0002-6510-9440.

${ }^{3}$ Especialista MBA em Gestão Pública pela Universidade Federal Fluminense - UFF/RJ; Graduação em SECRETARIADO EXECUTIVO pela UNIFACEX . ORCID: https://orcid.org/0000-0002-8341-7826.

${ }^{4}$ Mestre em Saúde Coletiva e Gestão Hospitalar; Especialista em Saúde Pública; Graduação em SERVIÇO SOCIAL pela Universidade Católica de Pernambuco. ORCID: https://orcid.org/0000-0002-5391-9366.
}

RC: 97932

Disponível em: https://www.nucleodoconhecimento.com.br/educacao/a-formacaodocente 
também, discute a importância das Tecnologias de informação e Comunicação (TIC's), no novo modelo de aulas remotas emergencial. Como resultados, constatouse que a solução encontrada, para que as aulas continuassem sem interrupções e o calendário acadêmico não sofresse alterações prejudiciais, foi a introdução de um novo formato de ensino, no qual substituía as aulas presenciais pelo modelo de aulas remotas através das TIC's. Portanto, a capacitação na formação docente do ensino nesse atual processo de aulas remotas é fundamental para o sucesso na educação no país, pois professores atualizados e inteirados com essas inovações tecnológicas são o elo e os mediadores do conhecimento entre discentes e as tecnologias.

Palavras-chaves: Ensino, Formação, COVID-19, Tecnologia, Conhecimento.

\section{INTRODUÇÃO}

No ano 2020 o mundo se deparou com uma crise na saúde pública mundial, ocasionada pela pandemia da COVID-19, as Organizações das Nações Unidas (ONU) decretaram para controle desse vírus o distanciamento social. Pois, era um vírus de pouco conhecimento e estudo, porém muito volátil, com isso a ONU acreditava naquele momento que pouca interação social evitaria o alastramento do vírus.

No Brasil os primeiros casos ocorreram no final de fevereiro de 2020 e foi decretado o isolamento em março do mesmo ano. Vários setores da economia foram afetados e tiveram que se modificar devido ao vírus.

A educação foi um dos setores da economia brasileira que tiveram que se adaptar ao uma nova realidade, uma vez que a interação entre docente e discente não poderia mais ocorrer de forma presencial devido ao alastramento do vírus COVID19. Surgindo assim, o ensino remoto emergencial mediado pelas Tecnologias de Informação e Comunicação (TIC's), trazendo novos desafios a serem enfrentados

RC: 97932

Disponível em: https://www.nucleodoconhecimento.com.br/educacao/a-formacaodocente 
pelos docentes em suas práticas pedagógicas. A COVID-19 se perdura até os tempos atuais e é definida pelo ministério da saúde, da seguinte forma:

A COVID-19 é uma doença causada pelo coronavírus, denominado SARSCoV-2, que apresenta um espectro clínico variando de infecções assintomáticas a quadros graves. De acordo com a Organização Mundial de Saúde, a maioria (cerca de $80 \%$ ) dos pacientes com COVID-19 podem ser assintomáticos ou oligossintomáticos (poucos sintomas), e aproximadamente $20 \%$ dos casos detectados requer atendimento hospitalar por apresentarem dificuldade respiratória, dos quais aproximadamente $5 \%$ podem necessitar de suporte ventilatório. (BRASIL, 2021)

A COVID-19 é pandemia que possui um grande poder de contaminação entre os seres humanos do planeta. Percebendo assim a necessidade de que sejam tomadas prevenções de contágios. Inclusive, o isolamento social, como está sendo aplicado nas instituições de ensino para garantir as práticas pedagógicas e a própria vida.

Houve a necessidade de reorganização das práticas pedagógicas no ensino básico brasileiro nas instituições de ensino do país ocasionado por uma pandemia que chegou de forma inesperada. Essa reorganização teve o intuito de melhorar o processo de ensino-aprendizagem nas instituições, pois tiveram que serem tomadas algumas medidas de readaptação para que houvesse a continuidade das aulas nas escolas e uma solução foi à introdução de um formato de modalidade remota emergencial com o auxílio das TIC's.

Ressaltando que a finalidade do ensino remoto não foi substituir as práticas pedagógicas já existentes, mas, sim, oportunizar acesso às informações de aulas não presenciais no intuito de preservar a saúde tanto dos discentes como dos docentes que estão em isolamento domiciliar.

Hoje, a formação docente tem proporcionado um resultado positivo no ensinoaprendizagem em relação aos discentes que estudam nas instituições de ensino de todo país. Desta forma, nota-se a relevância de sempre o profissional em educação está se reciclando constantemente com o objetivo de andar lado a lado com as possíveis alterações que venham a surgir no meio acadêmico. $\mathrm{Na}$ intenção de proporcionar sempre uma educação de qualidade aos discentes que lecionam.

RC: 97932

Disponível em: https://www.nucleodoconhecimento.com.br/educacao/a-formacaodocente 
Neste contexto, nos deparamos com a seguinte problemática: qual a possível solução encontrada para vencer os desafios que surgiram, em meio a pandemia do COVID-19 no Brasil, nas práticas pedagógicas docentes para que os calendários acadêmicos não sofressem alterações?

O ensaio é um estudo bibliográfico em educação, de abordagem qualitativa, visando expor e discutir pensamentos de autores relacionados ao tema proposto.

\section{CONTEXTUALIZANDO AS PRÁTICAS PEDAGÓGICAS NO ENSINO REMOTO EM TEMPO DE COVID-19}

As práticas pedagógicas no ensino brasileiro nas escolas, devido ao surgimento da COVID-19, tiveram que ser readequadas para que a segurança da vida fosse assegurada a todos que compõem ao núcleo de uma instituição de ensino: terceirizados, segurança, manutenção, limpeza, equipe administrativa, discentes e docentes. A solução aplicada para que houvesse essa segurança a todos foi introduzir aulas na modalidade remota de forma emergencial e com auxílio das TIC's. Lembrando que o objetivo do ensino remoto não foi trocar as práticas pedagógicas que já existiam, mas proporcionar um novo formato de instrução a distância que protegesse todos.

Houve essa estratégia de realização de um novo formato de aula não presencial para que a educação continuasse acontecendo e nas escolas do país. $O$ auxílio das TIC's como ferramentas de ensino-aprendizagem está sendo primordial para que haja as aulas remotas, pois, sem essas tecnologias, não seria possível que hoje os calendários acadêmicos no país.

A Arruda (2020, p.10), expõe o seu pensamento em relação de ter aulas remotas em meio à pandemia da seguinte forma:

A singularidade da pandemia deve levar também à uma compreensão de que a educação remota não se restringe à existência ou não de acesso tecnológico, mas precisa envolver a complexidade representada por docentes confinados, que possuem famílias e que também se encontram em condições

RC: 97932

Disponível em: https://www.nucleodoconhecimento.com.br/educacao/a-formacaodocente 
de fragilidades em suas atividades. O ineditismo leva a ações que precisam envolver toda a complexidade da qual faz parte.

Para o autor a educação remota não se aplica apenas a questão de ter tecnologia ou não nas escolas, e sim algo mais enigmático que envolve a saúde dos docentes e os seus familiares que poderiam ser afetados pelo COVID-19 caso houvesse aulas presenciais e não aulas remotas.

Neste formato de ensino, docentes em todo país consegue realizar as suas práticas pedagógicas adaptadas com as novas tecnologias e executarem as suas aulas com qualidade e segurança.

Para Imbérnom (2010, p. 36):

Para que o uso das TIC signifique uma transformação educativa que se transforme em melhora, muitas coisas terão que mudar. Muitas estão nas mãos dos próprios professores, que terão que redesenhar seu papel e sua responsabilidade na escola atual. Mas outras tantas escapam de seu controle e se inscrevem na esfera da direção da escola, da administração e da própria sociedade.

As TIC's são importantes aliados para que haja uma transformação positiva na educação, inclusive nas práticas pedagógicas. Porém, elas não podem ser apontadas como protagonistas dessa transformação por serem apenas tecnologias. A responsabilidade tem que vir conjuntamente da escola e do professor. E havendo essa conexão os problemas que vierem a surgir serão resolvidos de forma tranquila e compartilhados.

As práticas pedagógicas no ensino remoto que são utilizadas hoje em meio à pandemia precisam acompanhar as transformações em que as TIC's vêm ocasionando na sociedade contemporânea deste século, como: economia, social e política.

Não adianta implantar aulas remotas sem que o profissional em educação entenda o contexto atual das transformações em que vem ocorrendo na sociedade contemporânea. Desta forma, poderão fazer adaptações às suas práticas

RC: 97932

Disponível em: https://www.nucleodoconhecimento.com.br/educacao/a-formacaodocente 
pedagógicas do ensino-aprendizagem dentro das escolas de ensino básico onde lecionam e conseguir ajudar da melhor forma o funcionamento das aulas remotas.

\section{DISCUSSÕES SOBRE A FORMAÇÃO DOCENTE E A MEDIAÇÃO DO CONHECIMENTO}

Nota-se a relevância de discutirmos algumas definições de alguns autores sobre "formação docente" na intenção de aprofundarmos o tema em questão, e em seguida discutirmos a "mediação do conhecimento".

Segundo García (1999, p. 26), define:

a área de conhecimentos, investigação e de propostas teóricas e práticas que, no âmbito da Didática e da Organização Escolar, estuda os processos através dos quais os professores - em formação ou em exercício - se implicam individualmente ou em equipe, em experiências de aprendizagem através das quais adquirem ou melhoram os seus conhecimentos, competências e disposições, e que Ihes permitem intervir profissionalmente no desenvolvimento do seu ensino, do currículo e da escola, com o objetivo de melhorar a qualidade da educação que os alunos recebem.

Nota-se que Garcia defende que a formação docente se desenvolva na área do conhecimento. Podendo ser realizada individualmente ou em equipe no intuito que haja experiências de aprendizagem e consigam alavancar os seus conhecimentos e competências, melhorando, assim, a sua forma de lecionar e oportunizando uma educação de qualidade para os alunos que esses profissionais da educação ensinam.

Enquanto Nóvoa (2010, p. 186) faz a reflexão sobre a formação docente, quando diz: que "formar não é ensinar às pessoas determinados conteúdos, mas sim trabalhar coletivamente em torno da resolução de problemas. A formação se faz na produção, e não no consumo do saber". O professor precisa ter o discernimento que o conhecimento deve ser compartilhado no ensino em todo momento e abandonar a visão que apenas ele ensina e o aluno aprende, pois, a utilização desses métodos pelas instituições de ensino já está obsoleto e fadada ao fim.

RC: 97932

Disponível em: https://www.nucleodoconhecimento.com.br/educacao/a-formacaodocente 
$\mathrm{Na}$ atualidade, o modelo de ensino-aprendizado utilizado envolve a participação coletiva tanto de docentes como discentes, onde a troca de conhecimento é necessária para formar cidadãos críticos que consigam resolver problemas que venham a ocorrer, seja no meio educacional ou em suas próprias vidas, formando cidadãos prontos para contribuírem para a sociedade em que vivem.

Na verdade, o objetivo da escola contemporânea do século XXI é formar alunos que tenham o discernimento de identificar problemas, pensar e conseguir traçar estratégias para resoluções de problemas, ressaltando-se que o docente tem que ser o mediador entre discente e o conhecimento, inclusive quando houver as tecnologias envolvidas. Para Antunes (2002, p. 137): "Da mesma forma, os computadores também apresentam inúmeros recursos que, se bem utilizados, facilitam qualquer disciplina. O essencial, porém, é que o uso dessas tecnologias seja sempre precedido de um estudo e experimento por parte do professor".

O autor defende o uso de tecnologias como auxílio no ensino-aprendizagem pelos professores, mas sempre que essas tecnologias sejam testadas e supervisionadas por ele e colocando-se como mediador do ensino-aprendizagem.

Para Kenski (2007, p. 44): "ressalta que a presença de uma determinada tecnologia pode induzir profundas mudanças na maneira de organizar o ensino". O autor também afirma que o uso de tecnologias ajuda no ensino-aprendizagem, pois quando uma tecnologia é socializada e aplicada ao ensino a sua velocidade alavanca as possibilidades positivas do ensino-aprendizagem. Em relação às aulas remotas, esse formato de ensino possui o poder de aproximar educador do educando, não apenas por estarem virtualmente conectados em tempo real, mas também por conseguir ajudar a trocar de saberes entre eles.

Segundo Penteado (2000, p. 23):

afirma que: Quanto à escola, é necessário ajustar e/ou eliminar práticas e regras já existentes e concentrar esforços na criação de situações novas. Estão em jogo as normas institucionais, o currículo, a relação com os alunos, com pais e professores. Quanto ao professor, as mudanças envolvem desde

RC: 97932

Disponível em: https://www.nucleodoconhecimento.com.br/educacao/a-formacaodocente 
questões operacionais - a organização do espaço físico e a integração do velho com o novo - até questões epistemológicas, como a produção de novos significados para o conteúdo a ser ensinado.

Para o autor é necessário que as instituições de ensino planejem novas ações para que os educadores consigam ser os mediadores no processo de ensinoaprendizagem, onde as mudanças acontecerão desde as questões operacionais até as questões epistemológicas. Por isso, a importância do docente ser o mediador entre discente e o conhecimento e estar conduzindo esse processo de construção dos seus próprios saberes e dos alunos também.

Porém, para que o docente consiga ser um bom mediador do conhecimento terá que entender as transformações da sociedade multicultural para poder se aproximar da realidade cultural de seus estudantes. Para que isso aconteça é necessário que sejam implementadas nos currículos das instituições de ensino básico uma proposta de educação cultural direcionada a formação docente.

Para Moreira (2001, p. 43):

Que professores estão sendo formados, por meio dos currículos atuais, tanto na formação inicial como na formação continuada? Que professores deveriam ser formados? Professores sintonizados com os padrões dominantes ou professores abertos tanto à pluralidade cultural da sociedade mais ampla como à pluralidade de identidades presente no contexto específico em que se desenvolve a prática pedagógica? Professores comprometidos com o arranjo social existente ou professores questionadores e críticos? Professores que aceitam o neoliberalismo como a única saída ou que se dispõem tanto a criticá-lo como a oferecer alternativas a ele? Professores capazes de uma ação pedagógica multiculturalmente orientada?

Os questionamentos do autor demonstram a sua inquietação em relação aos desafios em que os professores vêm travando para conseguir se capacitar em uma sociedade multicultural que apresenta alterações a cada momento. Para que haja uma formação docente o profissional em educação precisa se adaptar a essa nova realidade e conduzir da forma mais atualizada e adequada as suas práticas docentes para que o ensino-aprendizagem flua de forma satisfatória, aproximando docente e discente.

RC: 97932

Disponível em: https://www.nucleodoconhecimento.com.br/educacao/a-formacaodocente 
A inserção de um currículo que alcance esse novo modelo de sociedade multicultural é necessária para que o ensino do país não seja engolido pelas mudanças, políticas, econômicas e culturais que vem acontecendo no mundo multicultural da atualidade.

A incorporação desses conteúdos nos currículos das instituições de ensino básico poderá ser sempre atualizada de acordo com as transformações que venham acontecer no mundo de forma a deixá-los próximos a realidades culturais atuais e as realidades dos discentes.

Desta forma, proporcionando aos alunos a conseguirem ficar habilitados como indivíduos com capacidades de serem críticos e capazes de fazer os questionamentos certos para evolução dos seus conhecimentos.

Segundo Moreira (2001, p. 68), relata que:

[...] capaz de promover a crítica do existente e o questionamento do que parece inscrito na natureza das coisas; capaz, então, de formar indivíduos não conformistas, rebeldes, transgressores, comprometidos com a luta contra toda e qualquer opressão. Decorre de considerá-la, em síntese, espaço público em que, em meio a práticas, relações sociais e embates, se produzem significados e identidades. Nesse espaço, novos tempos podem ser anunciados.

O autor explica que o currículo seja capaz de formar professores que tenham a capacidade de serem críticos e reflexivos e não formar indivíduos rebeldes, mas cidadãos comprometidos com a escola e o meio em que vivem.

Além dos educadores chamarem para a si a responsabilidade de ser o mediador entre o conhecimento e os seus discentes, eles precisaram respeitar a realidade dos seus estudantes. Uma vez que o mundo multicultural apresenta uma variedade de diversidades de homens e mulheres, cultural, religiosa, dentre outras.

Desta forma, o profissional de ensino básico precisa ter algumas condutas de tolerância para que haja um bom convívio entre discentes e docentes. Fazendo com

RC: 97932

Disponível em: https://www.nucleodoconhecimento.com.br/educacao/a-formacaodocente 
que o profissional em educação consiga aplicar da melhor forma suas práticas pedagógicas.

\section{CONSIDERAÇOES FINAIS}

A chegada da COVID-19 teve o poder de alterar todo o cotidiano da vida da sociedade mundial, inclusive do ensino nas instituições de ensino do Brasil. As práticas pedagógicas precisaram ser modificadas de forma quase que instantânea, pois, caso não fossem feitas as alterações das instituições de ensino do país, estas entrariam em colapso e os calendários seriam suspensos por tempos indeterminados.

Como resultados percebemos que a solução encontrada para que as aulas continuassem sem interrupções e o calendário acadêmico não sofresse alterações prejudiciais foi realizado à introdução de um novo formato de ensino, no qual substituía as aulas presenciais pelo modelo de aulas remotas emergências, mediante a adaptação das práticas pedagógicas em um novo modelo de ensino para que houvesse êxito na praticabilidade desta nova ação a ser aplicado a esse protótipo de ensino. Desta forma, as aulas poderiam ser lecionadas em tempo real e garantiria a segurança à vida.

Hoje, as TIC's estão sendo fundamentais para essa migração de novo formato de ensino, pois ela é uma ferramenta que consegue aproximar as pessoas virtualmente em tempo real, devido ao grande leque de inovações que ela oferece aos seus usuários.

Concluímos que a formação docente do ensino nesse atual processo de aulas remotas é fundamental para que haja o sucesso do ensino no país, pois professores atualizados e inteirados com essas inovações tecnológicas são o elo e os mediadores do conhecimento entre discentes e as tecnologias. A tecnologia é algo que vem fazendo a diferença no ensino, mas sem um condutor ela é apenas algo sem serventia alguma. Por isso, que é preciso que haja a formação docente

RC: 97932

Disponível em: https://www.nucleodoconhecimento.com.br/educacao/a-formacaodocente 
constantes nos assuntos pertinentes às suas disciplinas, mas também que seja voltada para as novas inovações tecnológicas que são atualizadas quase que diariamente.

\section{REFERÊNCIAS}

ANTUNES, Celso. Novas maneiras de ensinar, novas formas de aprender. Porto Alegre: ARTMED, 2002.

ARRUDA, E. P. (2020). Educação remota emergencial: elementos para políticas públicas na educação brasileira em tempos de Covid-19. Em Rede-Revista de Educação a Distância, 7(1), 257-275.

BRASIL, Ministério da Saúde. O que é COVID-19? 2021. Disponível em: https://www.gov.br/saude/pt-br/vacinacao/\#o-que-e-covid. Acesso: 05 jul. 2021.

GARCIA, Carlos. Formação de Professores: para uma mudança educativa. Portugal: Porto, 1999. MCLAREN, P. Multiculturalismo crítico. São Paulo: Cortez, 1997.

IMBERNÓN, Francisco. Formação docente e profissional: formar-se para a mudança e a incerteza. 7. Ed. São Paulo: Cortez, 2010.

KENSKI, V. M. Educando e Tecnologias: 0 novo ritmo da informação. São Paulo: Papirusp, 44. 2007.

MOREIRA, A. F. B. (2001). Currículo, cultura e formação de professores. Revista Educar, Curitiba, Editora da UFPR, n. 17, p. 5.

MOREIRA, A. F. B. (2001). A recente produção científica sobre currículo e multiculturalismo no Brasil (1995- 2000): avanços, desafi os e tensões. Revista Brasileira de Educação. 18, 65-81.

RC: 97932

Disponível em: https://www.nucleodoconhecimento.com.br/educacao/a-formacaodocente 
NÓVOA, António. Os Professores e a sua Formação num Tempo de Metamorfose da Escola. Educação \& Realidade, Porto Alegre, v. 44, n. 3, p. 115, 2019. Disponível em: https://www.scielo.br/pdf/edreal/v44n3/2175-6236-edreal44-03-e84910.pdf. Acesso em: 09 jul. 2021.

PENTEADO, Mirian. A informática em ação formação de professores, pesquisa e extensão - Miriam Penteado e Marcelo C. Borba (orgs.), Heloísa da Silva, Telma Gracias. São Paulo: Olho d'Agua 2000.

Enviado: Agosto, 2021.

Aprovado: Setembro, 2021. 